\title{
Design, Synthesis, Characterization, and In Vitro Evaluation of a New Cross-Linked Hyaluronic Acid for Pharmaceutical and Cosmetic Applications
}

\author{
Sabrina Sciabica ${ }^{1}$, Giovanni Tafuro ${ }^{2}$, Alessandra Semenzato ${ }^{2} \odot$, Daniela Traini ${ }^{3}{ }^{\infty}$, Dina M. Silva ${ }^{3}$, \\ Larissa Gomes Dos Reis ${ }^{3}$, Luisa Canilli ${ }^{4}$, Massimo Terno ${ }^{4}$, Elisa Durini ${ }^{1}$, Silvia Vertuani ${ }^{1, *}$, \\ Anna Baldisserotto ${ }^{1, *(1)}$ and Stefano Manfredini ${ }^{1}{ }^{1(1)}$
}

Citation: Sciabica, S.; Tafuro, G.; Semenzato, A.; Traini, D.; Silva, D.M.; Reis, L.G.D.; Canilli, L.; Terno, M.; Durini, E.; Vertuani, S.; et al. Design, Synthesis, Characterization, and In Vitro Evaluation of a New Cross-Linked Hyaluronic Acid for Pharmaceutical and Cosmetic Applications. Pharmaceutics 2021, 13, 1672. https://doi.org/10.3390/ pharmaceutics13101672

Academic Editor: Katarína Valachová

Received: 8 September 2021

Accepted: 11 October 2021

Published: 13 October 2021

Publisher's Note: MDPI stays neutral with regard to jurisdictional claims in published maps and institutional affiliations.

Copyright: (c) 2021 by the authors. Licensee MDPI, Basel, Switzerland. This article is an open access article distributed under the terms and conditions of the Creative Commons Attribution (CC BY) license (https:// creativecommons.org/licenses/by/ $4.0 /)$.
1 Department of Life Sciences and Biotechnology, University of Ferrara, Via L. Borsari 46, 44121 Ferrara, Italy; scbsrn@unife.it (S.S.); dre@unife.it (E.D.); smanfred@unife.it (S.M.)

2 Department of Pharmaceutical and Pharmacological Sciences, University of Padova, Via Marzolo 5, 35131 Padova, Italy; tafuro.giovanni.mds@gmail.com (G.T.); alessandra.semenzato@unipd.it (A.S.)

3 Macquarie Medical School, Department of Medical Sciences, Faculty of Medicine, Health and Human Sciences, Macquarie University \& Woolcock Institute of Medical Research, Sydney 2037, Australia; daniela.traini@mq.edu.it (D.T.); dina.silva@sydney.edu.au (D.M.S.); larissagomesreis@yahoo.com.br (L.G.D.R.)

4 Istituto Ganassini S.p.A., Via Carlo Boncompagni, 63, 20139 Milano, Italy; 1.canilli@ganassini.it (L.C.); dir.tecnica@ganassini.it (M.T.)

* Correspondence: vrs@unife.it (S.V.); bldnna@unife.it (A.B.); Tel.: +39-0532-455294 (S.V.); +39-0532-455258 (A.B.)

Abstract: Hyaluronic acid (HA), an excellent biomaterial with unique bio properties, is currently one of the most interesting polymers for many biomedical and cosmetic applications. However, several of its potential benefits are limited as it is rapidly degraded by hyaluronidase enzymes. To improve the half-life and consequently increase performance, native HA has been modified through cross-linking reactions with a natural and biocompatible amino acid, Ornithine, to overcome the potential toxicity commonly associated with traditional linkers. 2-chloro-dimethoxy-1,3,5-triazine/4methylmorpholine (CDMT/NMM) was used as an activating agent. The new product (HA-Orn) was extensively characterized to confirm the chemical modification, and rheological analysis showed a gel-like profile. In vitro degradation experiments showed an improved resistance profile against enzymatic digestions. Furthermore, in vitro cytotoxicity studies were performed on lung cell lines (Calu-3 and H441), which showed no cytotoxicity.

Keywords: hyaluronic acid; cross-linking; biocompatibility

\section{Introduction}

Over the past decade, hyaluronic acid (HA) has proven to be one of the best materials for application in various fields including pharmaceutical, food, and cosmetic applications, mostly due to its safety profile and unique physicochemical, biological, and viscoelastic properties.

HA is commonly used in ophthalmology to protect and lubricate the delicate eye tissues, supplement vitreous humour, and particularly in cataract surgery to replace lost vitreous fluid and to maintain the space and avoid the collapse of the eye tissue during the operation. On the other hand, HA is the main ingredient of many artificial tears that are produced with HA at different molecular weights and different polymer concentrations. Therefore, HA-based ophthalmic products are completely biocompatible and do not trigger foreign body reactions [1]; eye drops with hyaluronan derivatives with improved mechanical and biological properties have recently been formulated [2].

Because HA has both structural and regulatory functions in the processes of wound repair and re-epithelialization [3] as well as in the stimulation of collagen production, it has 
been considered as an appropriate candidate to support skin tissue regeneration. Therefore, it is often included, alone or in combination with other therapeutic agents, in topical formulations for the treatment of skin irritations and wounds including abrasions and burns as well as post-surgical, metabolic, and vascular ulcers. Generally, these products are used not only in the dermatological field but also in ophthalmology, otolaryngology rhinology, and dentistry [4]. Cross-linked HA hydrogel films have also been shown to accelerate the wound-healing process by promoting the re-epithelialization that typically occurs after damage [5]. Recently, biomimetic injectable biogels have been designed and developed via the cohesive molecular assembly of a network of polysaccharide polymers to provide HA with in situ gelling properties and avoid implant surgery [6].

Considering that hyaluronic acid is a natural anti-inflammatory and antioxidant, it represents a multifunctional agent for the treatment of certain lung diseases including airway diseases with a predominant inflammatory component such as rhinosinusitis, asthma, chronic obstructive pulmonary disease, cystic fibrosis, and primary ciliary dyskinesia [7-10]. All of these lung diseases are characterized by periodic or chronic inflammatory processes as a result of releasing inflammatory cytokines from the cells such as IL-6 and IL-8. These inflammatory mediators result in an increase in reactive oxygen species (ROS) and hence an increase in oxidative stress in the lungs [11] that play a key role in the regulation of wound healing. Recently, the use of polymers such as HA has also been reported in airway treatment because of their unique ability to retain water and regulate fluid balance in the lung interstitium. Due to its anti-inflammatory properties and tissue repair properties, the integration of exogenous high-molecular-weight hyaluronic acid can provide important results in reducing inflammation and, consequently, disease symptoms [12]. The use of $\mathrm{HA}$, as a therapeutic agent for the treatment of airway pathologies, is interesting because it opens the possible development of a new class of therapeutic agents resulting from the combination with molecules active for application in pulmonary therapy.

It is known that the concentration of HA in the skin decreases drastically with age, causing the formation of wrinkles [13,14]. For this reason, HA-based dermal fillers (DF) in recent years have aroused wide interest in the field of cosmetic surgery to restore lost volume and correct facial imperfections of the dermis [15]. There are several types of HAbased DFs on the market; they are usually cross-linked HA-based and show a structured network behaviour designed to persist in the body. The corrective effect is reversible and lasts from three to 24 months [16]. HA is also found in sunscreen products for its potential ability to protect the skin from harmful radiation due to its possible scavenging properties $[17,18]$. Due to its high hygroscopicity, HA can retain large quantities of water, providing hydration, conferring its application as a physical barrier depending on the molecular weight.

Although HA is an excellent biomaterial, many of its potential applications are limited due to its short half-life since after interaction, due to the CD44 receptor present on a variety of cell membranes, it is internalized and rapidly degraded by hyaluronidases $[19,20]$.

Chemical modifications of HA can be designed to enhance the half-life and modulate the desired therapeutic action while maintaining linear HA original properties, such as biocompatibility, biodegradability, and mucoadhesiveness [21]. To achieve this, derivatization strategies involving mainly two sites of HA functional groups have been used: the carboxylic group on the D-glucuronic acid and, more frequently, the hydroxyl group present on the $\mathrm{N}$-acetyl D-glucosamine.

The first example of a reaction is conjugation, in which a molecule is grafted onto a functionality of the polymer; the second type is the cross-linking of different chains through covalent bonds, using a chemical cross-linker [1].

Usually, the conjugation reaction is used to obtain the therapeutic effect [22] and can be used to add new reactive groups on the HA scaffold or to obtain a drug vehicle [1,23,24]. Cross-linking instead is mostly used to improve mechanical and rheological properties with consequent reduction of the degradation rate [25]. 
Known methods generally use synthetic cross-linkers including divinyl sulfone (DVS), 1,4-butanediol diglycidyl ether (BDDE) [26], and carbodiimide [1]. These cross-linkers can form a three-dimensional reticular structure with greater mechanical strength but have poor biocompatibility characteristics that can cause adverse reactions [27-29].

Therefore, several studies are focused on obtaining new and safe hydrogels to increase biocompatibility and biodegradability $[30,31]$. Specifically, recent studies have reported low (LMW) and high-molecular-weight HA (HMW) cross-linked by urethane bond formation, using a diisocyanate (BIED), which has a better profile than commonly used aryl di-isocyanates. These novel cross-linked hydrogels have shown potential use for vaccine administration (LMW HA) and cell encapsulation to reduce immune rejection of transplanted cells (HMW HA) [32]. Furthermore, this new material showed interesting bacteriostatic properties towards Staphylococcus (S.) aureus [33]. Another field of interest concerns the potential applications of innovative HA-based drug delivery systems in inflammatory skin diseases. HA-based nanoparticles and pluronic hydrogels were observed to enhance drug permeation through intact skin for the treatment of atopic dermatitis [34]. Furthermore, the use of gelatine and hyaluronic acid as the main materials for the preparation of absorbable hydrogel regeneration membranes has been proposed [35].

In this work, a new cross-linked HA has been developed, through a cross-linking technique that involves the formation of a reactive intermediate and the use of a new cross-linker, an ornithine methyl ester, a derivative from the natural and biocompatible aminoacidic precursor ornithine. Ornithine is a molecule naturally present in the human body where it is part of the Natural Moisturizing Factor (NMF) [36] and is therefore considered biocompatible and non-toxic. Ornithine is used in the nutraceutical and cosmetic field as a functional ingredient as it is recognized as an anti-ageing, immunostimulant, and promoter of tissue repair. Its chemical structure attracted our attention because of its use as a crosslinker and a possible carrier of active moieties through its homo-bifunctional amino residues. Due to the safety and beneficial effects of ornithine and HA, these two components were chosen for the synthesis of a new and innovative HA-based biopolymer with enhanced bioactivity, mechanical properties, and reduced toxicity. The availability of these innovative raw materials prompted us to investigate potential cosmetic, pharmaceutical, and nutraceutical applications, not only of the molecule as is, as active ingredients, but also as possible carriers of active molecules to the skin, as previously described $[37,38]$.

\section{Materials and Methods}

\subsection{Materials}

Sodium salt Hyaluronate (HA) isolated from Streptococcus equi with average $\mathrm{Mw}$ 1.2 MDa was purchased from Caldic (Origgio, Varese, Italy). Ornithine methyl ester ( $\mathrm{H}-\mathrm{Orn}-\mathrm{OMe} \cdot 2 \mathrm{HCl})$ was purchased from Bachem. 4-methylmorpholine (NMM), $\mathrm{NaCl}$, $0.025 \mathrm{M}$ sodium tetraborate, sulfuric acid, and acetonitrile were purchased from SigmaAldrich. 2-chloro-dimethoxy-1,3,5-triazine (CDMT) purchased from TCI. The phosphate buffer saline (PBS) was purchased from Sigma-Aldrich (Sigma-Aldrich SRL, Milano, Italy).

\subsection{Cross-Linked HA-Orn}

\subsubsection{Processing Parameters}

The synthesis of the product was conducted initially with EDC/NHS and then with CDMT/NMM as condensing agents to set up the ideal synthetic conditions to obtain an HA with a high degree of cross-linking and good yield. For the EDC/NHS route, several increasing stoichiometric ratios were used between HA: EDC: Ornithine but with poor results. From the scale-up study conducted, CDMT, in association with NMM, was found to be the most potent activator. Therefore, we switched to the latter as a condensing agent, leading to the synthesis of Ornithine cross-linked polymer, initially using an excess of both condensing agent and amino acid with a stoichiometric ratio of 1:4.5:3 between HA:CDMT/NMM:Ornithine. This ratio was subsequently reduced to 1:3:1.5 as it was able to offer the same product in terms of crosslinking and yield, 
avoiding reagent waste. The degree of cross-linking was directly proportional to the number of molecules forming double links, which play an important role in the viscoelastic properties of HA. It is important to evaluate the desired degree of cross-linking for the development and commercialization of new HA products, especially for biomedical and cosmetic applications. A polymer with a high degree of cross-linking corresponds to a slower degradation rate, degrading slower in the body. The result of chemical cross-linking is a three dimensional HA hydrogel that could retain water within its cross-linked network but does not dissolve readily in water. This allows for greater resistance resulting from a reduction in the access of digestive enzymes in the polymeric network and the consequent hydrolytic cut.

\subsubsection{Synthesis of Cross-Linked HA-Orn}

HA sodium salt (264 mg; $0.66 \mathrm{mmol}$ of carboxylate group) was uniformly dissolved in $52 \mathrm{~mL}$ of deionized water before the addition of $35 \mathrm{~mL}$ of acetonitrile. The homogeneous solution was cooled in an ice bath for $0.5 \mathrm{~h}$, and $347.5 \mathrm{mg}$ of CDMT (1.98 mmol) was added. After $1 \mathrm{~h}, 261.9 \mathrm{mg}$ of Orn-OMe and $2 \mathrm{HCl}(0.99 \mathrm{mmol})$ were added. The $\mathrm{pH}$ value was adjusted to 4 with $\mathrm{HCl} 0.5 \mathrm{M}$, and then $217.8 \mu \mathrm{L}$ of NMM (1.98 mmol) was added and the reaction was stirred $(\sim 400 \mathrm{rpm})$ overnight. The HA-Orn product was then purified using a dialysis membrane tube with an Mw cut-off of 3.5 KDa (Thermo Fisher Scientific, Italy) against $\mathrm{H}_{2} \mathrm{O}$ for $24 \mathrm{~h}$, followed by $\mathrm{NaCl}(0.1 \mathrm{M})$ for two days and finally against $\mathrm{H}_{2} \mathrm{O}$ for two days. The purified HA-Orn was lyophilized using a Lio-5P lyophilizer (Vetrotecnica S.r.l., Padua, Italy), resulting in a white powder with a 73\% (280 mg) yield. NMR spectra were registered with a spectrometer Mercury Plus-400 (Varian) at $400 \mathrm{MHz}$ at room temperature. HA-Orn ${ }^{1} \mathrm{H}$ NMR $\left(400 \mathrm{MHz}, \mathrm{D}_{2} \mathrm{O}\right) \delta$ ppm: $4.43(\mathrm{~m}, 3 \mathrm{H}, 2 \mathrm{O}-\mathrm{CH}-\mathrm{O}$ anomeric carbon of HA; $-\mathrm{CH}-\alpha$ of Ornithine), 3.97-3.09 (m, 15H, C-CH-O of HA; $-\mathrm{OCH}_{3}$ of Ornithine), $2.92\left(\mathrm{~m}, 2 \mathrm{H}, \mathrm{CH}_{2} \delta\right.$ of ornithine), 1.97 (s, 3H, $\mathrm{CO}-\mathrm{CH}_{3}-\mathrm{N}$ of HA), $1.80-1.56$ (m, $4 \mathrm{H},-\mathrm{CH}_{2} \beta$ and $-\mathrm{CH}_{2} \gamma$ of ornithine).

\subsection{Chemical-Physical Characterization of HA-Orn}

\subsubsection{Fourier-Transform Infrared Spectroscopy (FTIR)}

FTIR measurements were performed on dry powder samples using an FTIR spectrophotometer (PerkinElmer Spectrum 100) and an ATR method (attenuated total reflectance) scanned from 4000 to $650 \mathrm{~cm}^{-1}$, at room temperature. The samples were placed directly on the crystal, and FTIR spectra were obtained after eight scans with a resolution of $1 \mathrm{~cm}^{-1}$. IR ( $\left.\mathrm{cm}^{-1}\right)$ : 3267, 1730, 1617,1640, 1515, 1409, 1010.

\subsubsection{Differential Scanning Calorimetry (DSC)}

The heat transition of the samples was determined using a differential scanning calorimeter DSC60A (Shimadzu Corporation Kyoto, Kyoto, Japan) calibrated with a pure indium standard. Samples ( 2 to $6 \mathrm{mg}$ ) were placed in hermetically sealed aluminium pans and heated from $25^{\circ} \mathrm{C}$ to $300{ }^{\circ} \mathrm{C}$ at $10{ }^{\circ} \mathrm{C} / \mathrm{min}$. Measurements were performed in an inert nitrogen atmosphere purged at a flow rate of $45.0 \mathrm{~mL} / \mathrm{min}$. The endothermic and exothermic peaks were elaborated using TA-60 WS system software (Shimadzu corporation Kyoto, Japan).

\subsubsection{Scanning Electron Microscopy (SEM)}

Lyophilized samples of HA and HA-Orn were observed using a field emission scanning electron microscope (Zeiss EVO 40XVP, Carl Zeiss Pty Ltd., Oberkochen, Germany), with a voltage acceleration of $20 \mathrm{kV}$. Samples were deposited on carbon sticky tabs, analyzed in variable pressure mode, scanned, and photographed randomly.

\subsubsection{Swelling Measurement}

The swelling degree (SD) of HA-Orn is defined as the ratio between the weight of the swollen gels (Ws) after prolonged dialysis in aqueous media at different $\mathrm{pH}$ values vs. 
the weight of the dry gels $(\mathrm{Wd})$. Dry lyophilized samples $(100 \mathrm{mg})$ were exactly weighed before loading in a dialysis tube with $300 \mathrm{~mL}$ of $\mathrm{PBS}$ at $\mathrm{pH}$ values equal to $4.5,6.5$, and 9, and deionized $\mathrm{H}_{2} \mathrm{O}$ at $25^{\circ} \mathrm{C}$. The weight of each swollen sample after $24 \mathrm{~h}$ was determined to calculate SD according to Equation (1):

$$
\% \mathrm{SD}=\mathrm{Ws} / \mathrm{Wd}
$$

\subsubsection{Rheological measurement}

The rheological analyses were performed using a Physica MCR-101 rheometer (Anton Paar GmBH, Graz, Austria), equipped with PP50-P2 parallel plate geometry with serrated surfaces. The gap between the surfaces of the plates was fixed at $1 \mathrm{~mm}$. A Peltier system ensured a temperature of $23 \pm 0.05^{\circ} \mathrm{C}$. Before the measurements, all samples were maintained at the initial temperature for $1 \mathrm{~min}$. A Controlled Shear Rate (CSR) test was conducted in triplicate under continuous flow conditions, recording the viscosity $(\eta)$ values of the samples at increasing shear rates ranging from 0.001 to $1000 \mathrm{~s}^{-1}$. The flow curves obtained were fitted with the Carreau-Yasuda mathematical model (Equation (2)), which describes the shear-thinning behavior and allows the calculation of the zero-shear viscosity

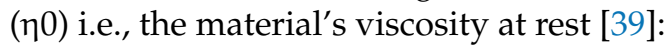

$$
\tau=\eta \infty \dot{\gamma}+\frac{(\eta 0-\eta \infty) \dot{\gamma}}{\left[1+(\lambda \dot{\gamma})^{2}\right]^{\frac{1-n}{2}}}
$$

The viscoelastic behavior under oscillatory flow conditions was measured using the trends of the storage $\left(\mathrm{G}^{\prime}\right)$ and the loss $\left(\mathrm{G}^{\prime \prime}\right)$ modules [40]. An Amplitude Sweep (AS) test was performed at a fixed value of frequency $(1 \mathrm{~Hz})$, varying the strain $(\gamma)$ from 0.01 to $1000 \%$ to identify the Linear Viscoelastic Region (LVER). A Frequency Sweep (FS) test was conducted at a fixed value of strain from LVER, increasing the values of frequency in a range from 10 to $0.01 \mathrm{~Hz}$ to study the materials' inner structure and physical stability [41]. The $G^{*}$ parameter is an indicator that measures some physical-mechanical properties such as the firmness and the flexibility of the material structure (Equation (3)).

$$
|G *|=\sqrt{G^{\prime 2}+G^{\prime \prime 2}}
$$

The damping factor $(\tan \delta)$, calculated from the ratio between the loss modulus $G^{\prime \prime}$ and the storage modulus $G^{\prime}$, was used to describe the predominant component between solid-elastic or liquid-viscous.

\subsubsection{Water Content}

The relative moisture sorption of freeze-dried HA and HA-Orn after exposure to different humidity levels (0-90\% RH) was analyzed by Dynamic Vapour Sorption (DVS, DVS-1, Surface Measurement Systems Ltd., London, UK). Each sample was placed in an aluminum pan and exposed to two cycles of $0-90 \%$ relative humidity (RH) at $25^{\circ} \mathrm{C}$, at $10 \% \mathrm{RH}$ increments. The equilibrium moisture content in each humidity phase was determined as a change in the ratio of mass versus time $(\mathrm{dm} / \mathrm{dt})$ of $0.0005 \% \mathrm{~min}^{-1}$.

\subsection{Enzymatic Degradation Test}

\subsubsection{Sample Disc Preparation}

HA and HA-Orn were prepared for the enzymatic degradation test by forming solid discs. Briefly, $1 \mathrm{~mL}$ of an aqueous solution $(1.5 \% \mathrm{w} / \mathrm{v})$ of each sample was poured into spherical molds with a diameter of $10 \mathrm{~mm}$ and then lyophilized. The dehydrated samples were then pressed to form compact discs, weighing $15 \mathrm{mg}$ and $1 \mathrm{~mm}$ thick. 


\subsubsection{In Vitro Degradation}

A stock solution of hyaluronidase from bovine testes (type IV-S powder, 1045 units $/ \mathrm{mg}$, lot SLCC9109, from Sigma Aldrich) was prepared at a concentration of 50 units $/ \mathrm{mL}$ in PBS. The discs of each sample in this enzymatic solution were kept under agitation at $37^{\circ} \mathrm{C}$ for different test times (up to $24 \mathrm{~h}$ ) to verify the glucuronic acid released. To verify the absence of degradation phenomena due to temperature, a control was carried out on each test sample without HAse at the same temperature (data not shown).

\subsubsection{Carbazole Assay}

At pre-determined time points, $200 \mu \mathrm{L}$ of supernatant was withdrawn and added to $3 \mathrm{~mL}$ of $0.025 \mathrm{M}$ sodium tetraborate in tubes containing sulfuric acid. The samples were vortexed for $10 \mathrm{~s}$ and then boiled for $10 \mathrm{~min}$ at $100{ }^{\circ} \mathrm{C}$. After cooling, $100 \mu \mathrm{L}$ of $0.0125 \%$ carbazole reagent in $\mathrm{EtOH}$ (absolute) was added to the samples, and the reaction was started by boiling for further $15 \mathrm{~min}$. The amount of GlcA produced after degradation was monitored by absorbance reading with a spectrophotometer UV-31 SCAN ONDA (Giorgio Bormac S.r.l., Carpi (Modena), Italy) at $523 \mathrm{~nm}$. A blank control was prepared with phosphate buffer only.

\subsection{Biological Assays}

\subsubsection{Cells Culture}

Calu-3 and NCI-H441 cell lines (carcinoma-derived epithelia, ACTT, Rockville, MD, USA) were chosen as a model of respiratory cells due to their ability to grow in an air-liquid interface and produce tight junctions and mucus, similar to the physiological conditions observed in the lung. Both cell lines were cultured in $75 \mathrm{~cm}^{2}$ flasks and were maintained in humidified $95 \%$ air, $5 \% \mathrm{CO}_{2}$ atmosphere, at $37^{\circ} \mathrm{C}$. Calu-3 was cultured in Dulbecco's Modified Eagle's Medium/F-12 supplemented with 1\% $(v / v)$ non-essential amino acids, $1 \%$ $(v / v) 200 \mathrm{mM}$ L-glutamine solution, and 10\% $(v / v)$ fetal bovine serum (FBS), while H441 cells were cultured in RPMI-1640 medium, supplemented with 10\% $(v / v)$ FBS. Media were changed 2-3 times per week until confluency; then cells were passaged using trypsin at 1:3 and 1:7 ratios for Calu-3 and $\mathrm{H} 441$ cells, respectively. To establish an air-liquid interface (ALI), both cell lines were seeded at $3 \times 10^{4}$ cells per well of a Transwell polyester insert containing $100 \mu \mathrm{L}$ in the apical chamber and $600 \mu \mathrm{L}$ in the basal chamber. The medium from the apical chamber was removed $24 \mathrm{~h}$ after seeding and every day afterwards until an ALI was achieved, while the medium from the basal chamber was replaced every second day up to 14 days of culture. For H441, a differentiation medium was used on the basal chamber from day 2 from seeding the cells consisting of RPMI-1640 medium supplemented with $200 \mathrm{nM}$ dexamethasone (Sigma) and 1\% $(v / v)$ insulin-transferrin-selenium supplement (100×, Gibco, Sidney, Australia).

\subsubsection{MTS Assay for Cytotoxicity}

Cells were seeded at a density of $50 \times 10^{4}$ cells/well in a 96-well plate. After $24 \mathrm{~h}$, the media were removed and replaced with $100 \mu \mathrm{L}$ of the raw materials prepared in HBSS. After $24 \mathrm{~h}$ incubation, $20 \mu \mathrm{L}$ of MTS reagent was added to the wells and read after $3 \mathrm{~h}$ at $490 \mathrm{~nm}$. The solutions were prepared as a serial dilution in the range of $0.009-0.30 \%(w / v)$ for HA and HA-Orn. DMSO 20\% was used as the control for cell death.

\subsection{Statistical Analysis}

All the results are reported as the mean \pm standard error of at least three separate determinants. The statistical software GraphPad Prism (version 8.2.1) was used to test for significance by performing an unpaired $t$-test for significance in each experiment. Significance was determined as $p<0.05$. 


\section{Results}

\subsection{HA-Orn Cross-Linked Synthesis}

The HA cross-linked product was successfully prepared by amidation of the carboxyl groups through a synthetic procedure adapted from the Bergman method [42] using the amino acid Ornithine methyl ester as a cross-linker to form diamide bonds between the chains of HA. CDMT, in association with NMM, was found to be the most efficient activator. The synthesis of HA-Orn was carried out at room temperature with an excess of both activating agent and the amino acid at a ratio of HA: CDMT: amino acid of 1: 3:1.5.

The reaction initially involved the activation of the carboxylic acid with CDMT to form the intermediate, activated HA; then, NMM was added to the mixture in equimolar ratio to CDMT to neutralize the chloride ions formed (Figure 1). A purification step by exhaustive dialysis was conducted until the resulting hydrogel was completely purified from any detectable residual cross-linker agent to finally obtain a white dry powdery product.

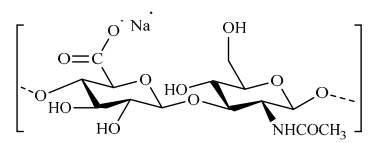

HA

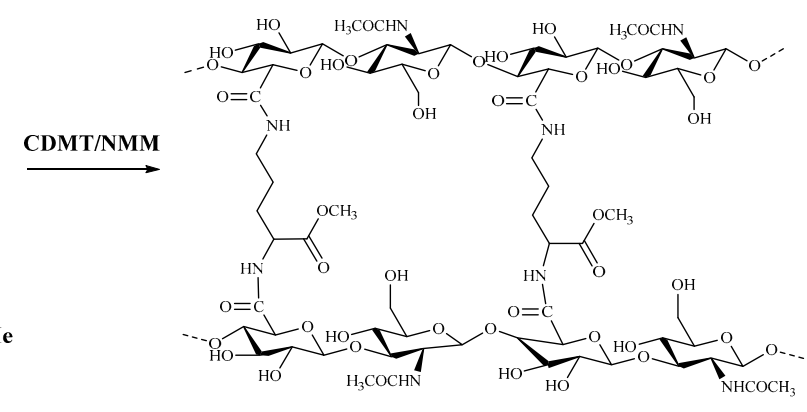

Figure 1. Synthetic scheme of HA crosslinked with the Ornithine methyl ester.

\subsection{Physico-Chemical Characterization Methods}

\subsection{1. ${ }^{1} \mathrm{H}-\mathrm{NMR}$}

${ }^{1} \mathrm{H}-\mathrm{NMR}$ spectroscopy (Figure 2) was used for the characterization of the chemical modification that occurred on native HA. Specifically, the degree of modification was quantified by calculating the integration of a signal belonging to the cross-linker to the characteristic peak of the native HA at $1.9 \mathrm{ppm}$ that was specific for the protons of the methyl proton group of $\mathrm{N}$-acetyl glucosamine.
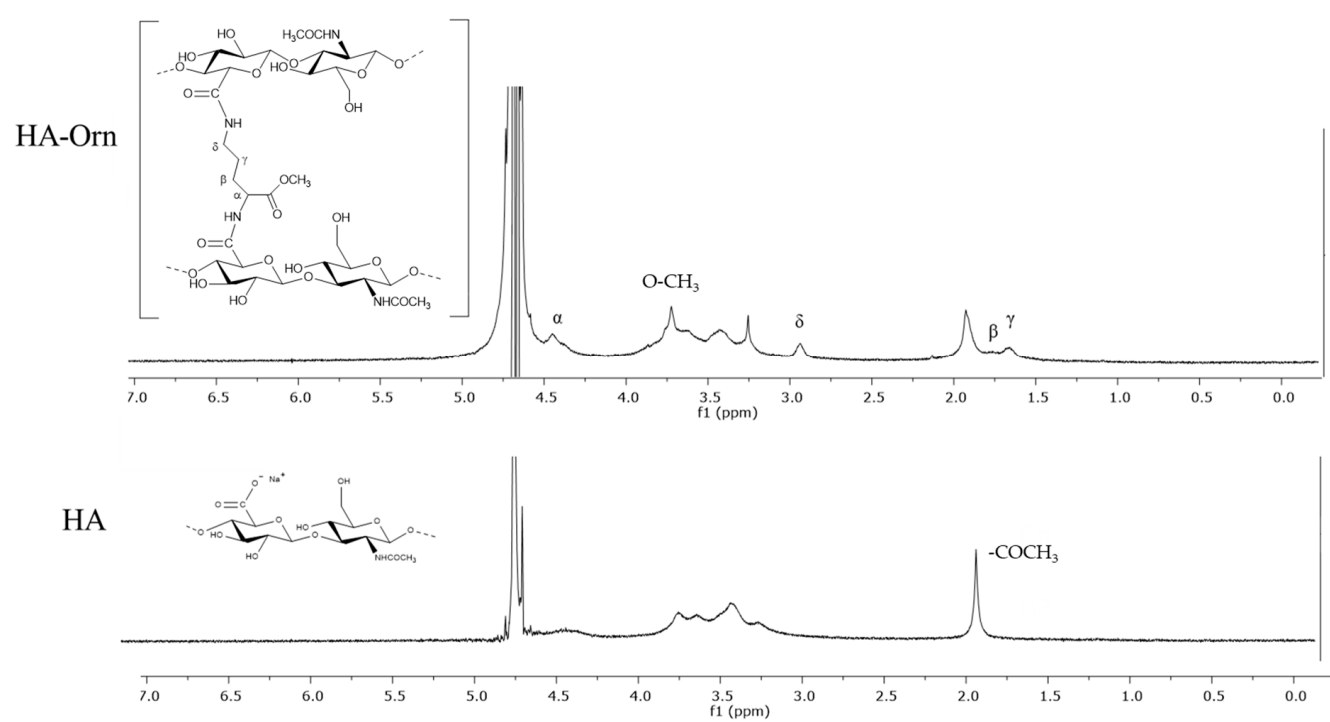

Figure 2. ${ }^{1} \mathrm{H}-\mathrm{NMR}$ spectrum of native $\mathrm{HA}$ and cross-linked HA-Orn recorded in $\mathrm{D}_{2} \mathrm{O}$. 
The spectra of hyaluronic samples gave enlarged signals due to the viscosity of the product in the solution. The peaks of the methyl groups of the Ornithine side chain were selected since they did not overlap with the peaks of the native HA, allowing for an easy calculation of the degree of modification.

The HA-Orn spectrum displayed three characteristic peaks: two wide signals at $1.56 \mathrm{ppm}\left(-\mathrm{CH}_{2} \gamma\right)$ and $1.72 \mathrm{ppm}\left(-\mathrm{CH}_{2} \beta\right)$ and the methoxy group at $2.89 \mathrm{ppm}$.

In all spectra, the multiplet of signals in the region from 3.2 to $3.9 \mathrm{ppm}$ corresponded to the protons of the HA component. However, HA also showed a large signal at $4.4 \mathrm{ppm}$ related to the two anomeric protons. In the spectra of HA-Orn, this signal overlapped with the signals of the methyl groups in $\alpha$ at $4.5 \mathrm{ppm}$. From the calculation of the ratio between the two reference signals, it was found that the degree of modification was estimated at around 35\% for HA-Orn; these values corresponded to the amount of Ornithine crosslinked with native HA.

\subsubsection{IR Spectroscopy}

Figure 3 shows the difference in the IR spectra between HA and HA-Orn. Native HA showed main absorption bands at $3267 \mathrm{~cm}^{-1}$ corresponding to $\mathrm{O}-\mathrm{H}$ and $\mathrm{N}-\mathrm{H}$ group stretching; a double band at $1617 \mathrm{~cm}^{-1}$ and $1409 \mathrm{~cm}^{-1}$ was attributed to the asymmetric and symmetric $\mathrm{C}=\mathrm{O}$ stretching modes of the planar carboxylate groups, and a band at $1010 \mathrm{~cm}^{-1}$ indicated $\mathrm{C}-\mathrm{OH}$ stretching vibrations. HA-Orn profiles showed (1) the appearance of a $\mathrm{C}=\mathrm{O}$ amide band at $1640 \mathrm{~cm}^{-1}$, which corresponded to the new amide bonds from the cross-linking reaction; (2) the band related to the carboxylate groups at $1600-1400 \mathrm{~cm}^{-1}$ disappeared with an increase in the intensity of the NH group peak at about $3200 \mathrm{~cm}^{-1}$; furthermore, a NH bending band at $1515 \mathrm{~cm}^{-1}$ was observed; and (3) another new band was evident at around $1730 \mathrm{~cm}^{-1}$ relative to the carbonyl group of the methyl ester on the amino acid. These results agree with the expected product after the cross-linking reaction, providing further evidence of the desired bond formation.

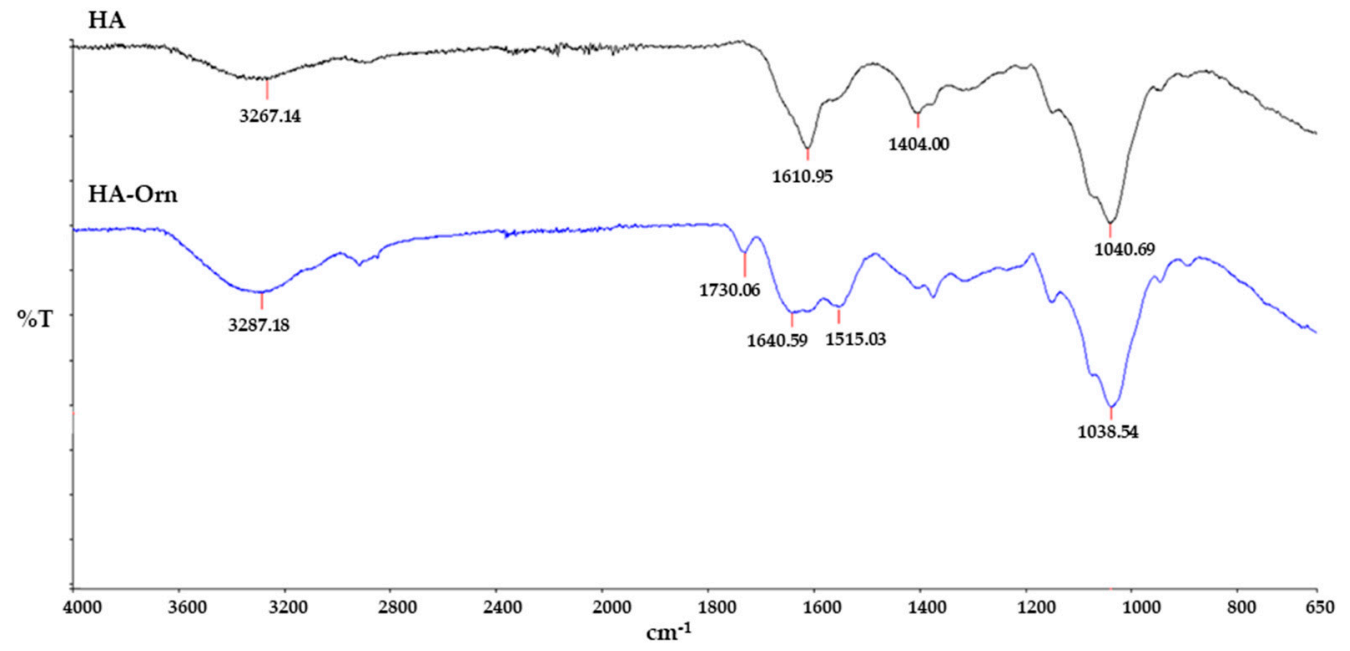

Figure 3. FTIR spectra of native HA and cross-linked HA-Orn.

\subsubsection{Thermal Analysis: DSC}

Chemical cross-linking leads to chemical-physical changes that can be correlated with different in vitro and in vivo behaviours with respect to native HA. To study how the chemical modification could influence the interactions between the polymer chains and the water content, the thermal behaviour of HA-Orn was investigated by differential scanning calorimetry [43], a thermal analysis able to provide information on their hydration and thermal resistance properties [44-46]. The DSC technique is based on the different temperature demands between the reference and the sample as well as the measurement of the heat absorbed or released by the system when the temperature changes following structural changes. 
The HA profile (Figure 4) showed two peaks: an endothermic peak around $101{ }^{\circ} \mathrm{C}$, suggested the temperature of dehydration, followed by an exothermic peak attributable to the sample decomposition temperature at $238^{\circ} \mathrm{C}$. A similar profile was shown by HAOrn but with lower onset temperature values: a large endothermic peak was observed at $97.4{ }^{\circ} \mathrm{C}$ associated with the loss of moisture (residual after lyophilization) followed by an exothermic peak at a lower temperature $\left(232^{\circ} \mathrm{C}\right)$, corresponding to the decomposition of HA-Orn.

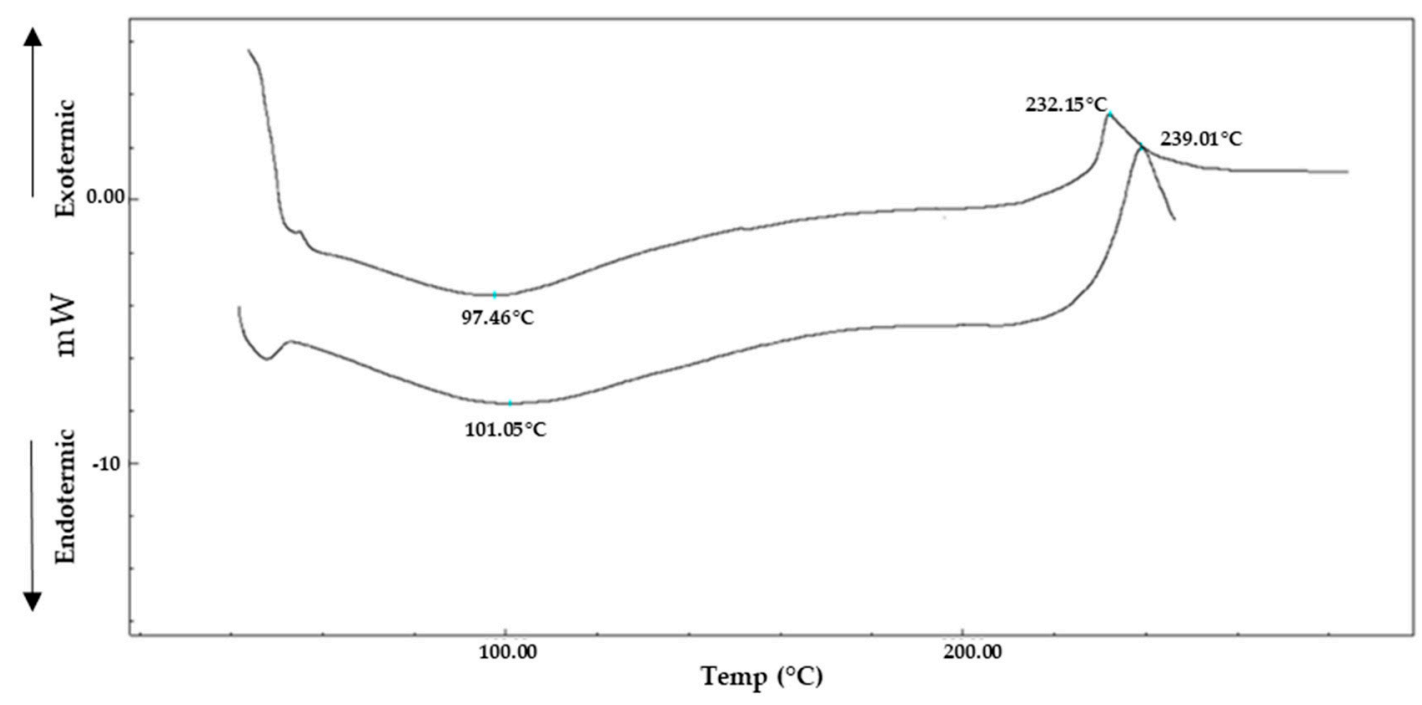

Figure 4. DSC thermograms of native HA and HA-Orn.

The shift of the endothermic peak in the cross-linked product reflects lower water retention. Furthermore, the exothermic peak of HA-Orn was present at a lower temperature of $\left(\sim 7^{\circ} \mathrm{C}\right)$ than native HA due to the presence of amino acid in the new structure. These observations showed that the cross-linking produced a new material with a different structural organization from the originator.

\subsubsection{Scanning Electron Microscopy (SEM)}

In Figure 5, SEM surface images of the native HA and HA-Orn cross-linked are shown. Native HA images (Figure 5, panels a1 and a2) showed a filamentous and irregular structure, while HA-Orn novel hydrogel showed a well-defined scaffold-like structure. HA-Orn (Figure 5, panels b1 and b2) showed a firmer and evenly distributed structure with small pores.

Compared to native HA, HA-Orn is characterized by a network structure. From the SEM images, interconnectivity between the solid structures seems to emerge as a characteristic of the HA-Orn product. It can be hypothesized that these structural characteristics could allow the new polymer, when placed in an aqueous medium, to behave like a hydrogel [47]. 

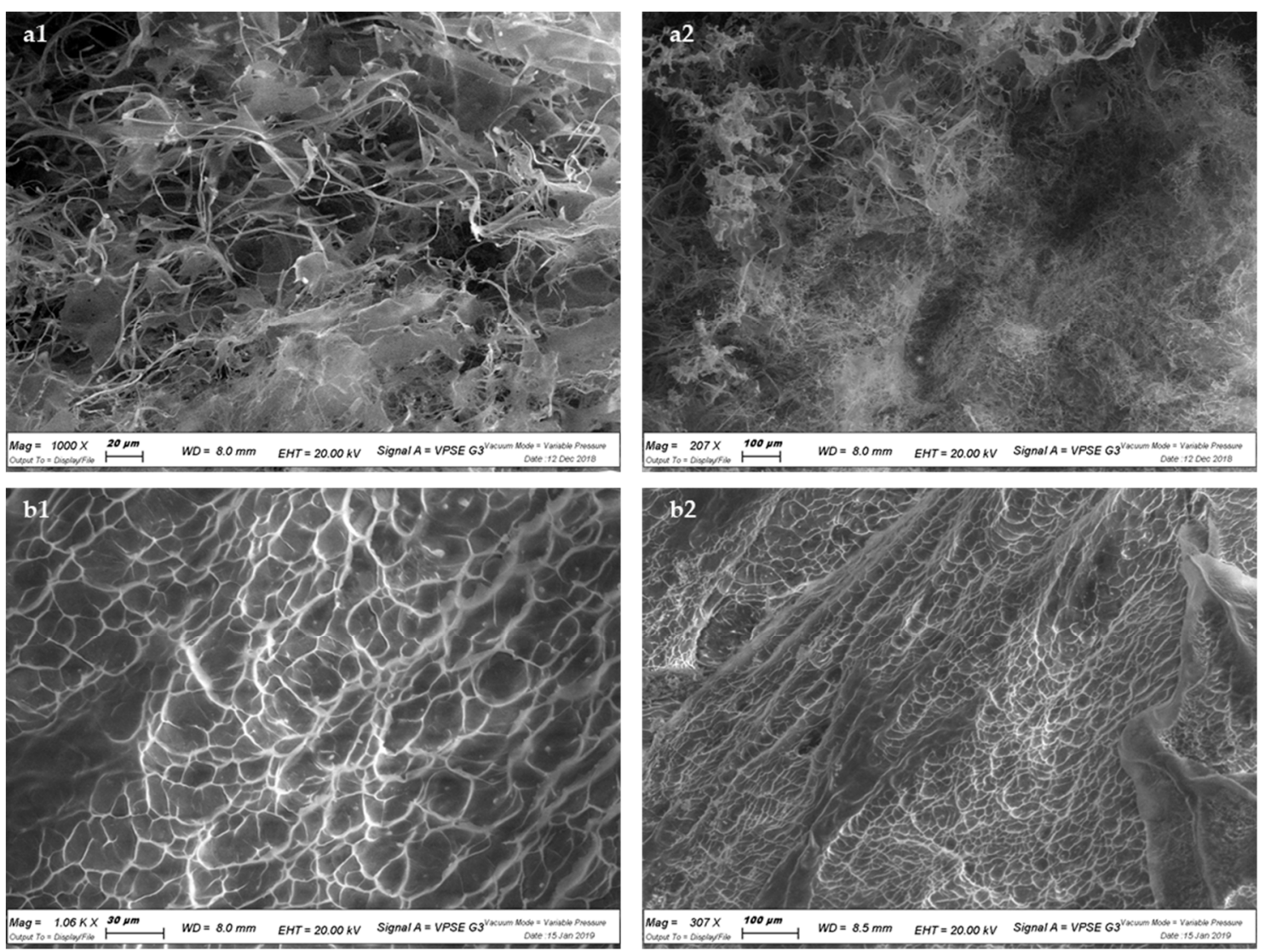

Figure 5. SEM images of HA (panels a1,a2) and HA-Orn (panels b1,b2). SEM Scale bar: $20 \mu \mathrm{m}$ (panel a1), $100 \mu \mathrm{m}$ (panels $\mathbf{a 2 , b 2 ) , ~} 30 \mu \mathrm{m}$ (panel b1).

\subsubsection{Swelling Ratio Measurement}

Control of the rate and extent of hydration of the material is necessary to promote cell adhesion and subsequent prolonged activity; crosslinking strategies are used to achieve this goal [48], with high swelling values linked to a lower cross-linking density [1]. In particular, when cross-linked, HA can form a three-dimensional network capable of swelling and modulating the release of the loaded active ingredients, such as antibacterial molecules [49], anti-inflammatory substances [50], proteins, and antibodies [51]. Figure 6 presents the 24-h swelling of the cross-linked HA-Orn samples at $25^{\circ} \mathrm{C}$ for a range of $\mathrm{pH}$ values, which are representative of some biological fluids (4.5-9.5) [52,53]. Linear HA uncross-linked dissolves rapidly when immersed in an aqueous medium, and therefore the swelling could not be measured.

The results obtained are in agreement with the swelling values typical of hydrogels. The swelling property of HA-Orn decreases with increasing $\mathrm{pH}$, suggesting the influence of the ionic strength of the buffer. The highest swelling of HA-Orn was observed when the sample was immersed in distilled water, possibly due to electrostatic repulsion between the anionic charged groups of the carboxyl group (pKa 2.9), which allows a greater distention of the derivatized HA chains. The difference in $\mathrm{pH}$ can easily explain the different swelling behaviours, with the reduced swelling at basic $\mathrm{pH}$ possibly due to the lack of ionization of the carboxyl groups. The results suggest that the hydrogel exhibits a certain degree of $\mathrm{pH}$ reactivity, a phenomenon that could be exploited to modulate the swelling degree of cross-linked hydrogels, potentially useful for drug release applications. 


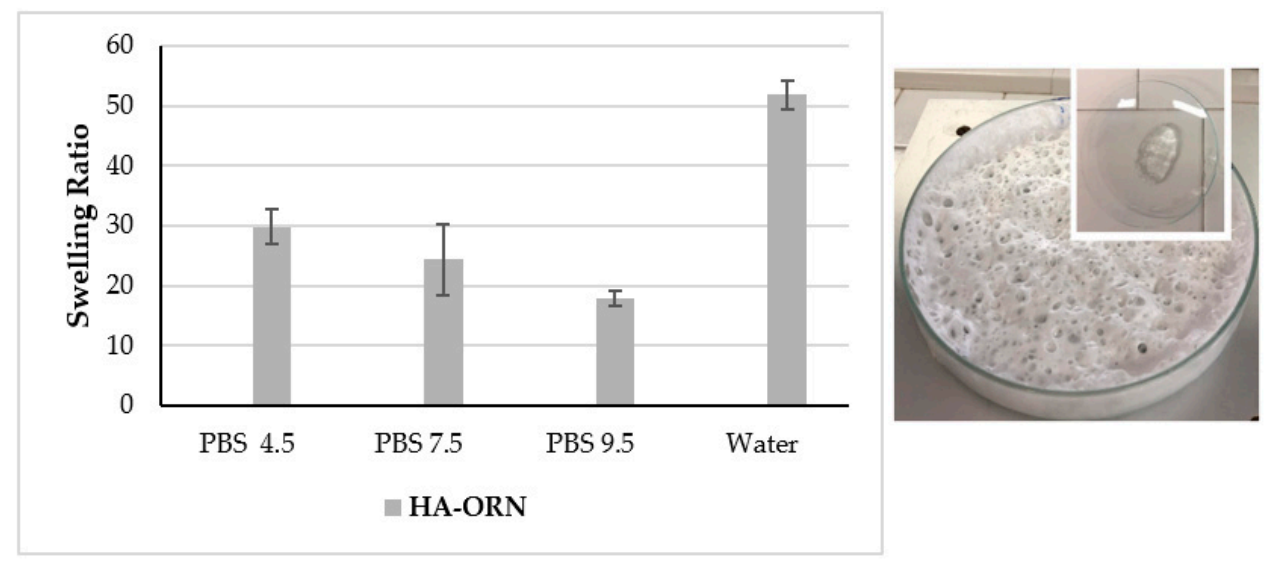

Figure 6. Left: Swelling ratio of HA-Orn at different $\mathrm{pH}$ values $(n=3$; mean $\pm \mathrm{StDev})$ in PBS. Right: the behavior of HA-Orn before and after the addition of water.

\subsubsection{Rheology}

A Controlled Shear Rate test was conducted on the cross-linked hyaluronic acid dispersion prepared at a concentration of $2 \%(w / w)$ of raw material to analyze the viscosity as a function of the shear rate, ranging from 0.001 to $1000 \mathrm{~s}^{-1}$. HA-Orn showed a shearthinning behavior since the viscosity values decreased as the shear increased (Figure 7, panel A). HA-Orn reached higher viscosity values than HA, due to strong interactions between the material's cross-linked chains and the solvent, forming a three-dimensional network, in which the aqueous solvent is trapped. Indeed, the introduction of chemical crosslinking between the polymer chains leads to a permanent stable network where the individual chain's flow unit is lost, and consequently, the intrinsic mobility of the resulting molecule undergoes a substantial reduction. The calculated viscosity at rest $(\eta 0)$ for HAOrn was $9578.38 \mathrm{~Pa} \cdot \mathrm{s}$. The viscosity rapidly decreased as a function of the shear rate, as shown in Figure 7, which means that the polymeric chains started to align toward the direction of the flow. HA dispersion showed a viscosity value more than three orders of magnitude lower than that of HA-Orn. The calculated value of $\eta_{0}$ for HA was $1.33 \mathrm{~Pa} \cdot \mathrm{s}$.

The viscoelastic behaviour of both samples was investigated under oscillatory flow conditions. By increasing the strain values from 0.01 to $1000 \%$, at a fixed oscillation frequency of $1 \mathrm{~Hz}$, an Amplitude Sweep test was conducted. This test allowed identification of the Linear Viscoelastic Region (LVER) in which the elastic $G^{\prime}$ and the viscous $G^{\prime \prime}$ moduli were not dependent on strain showing a constant trend (Figure 7, panel B).

According to the flow condition experiment, the two samples showed very different viscoelastic properties. The HA solution had a liquid-like behaviour with $\mathrm{G}^{\prime \prime}$ always dominating over $\mathrm{G}^{\prime}$ for the entire range of amplitude strain investigated. On the contrary, HA-Orn dispersion was characterized by high moduli values, with $G^{\prime}$ over $G^{\prime \prime}$ in the LVER, indicating a predominantly elastic behaviour of the material due to the highly swollen network formed in water. After this region, increasing the amplitude strain, $G^{\prime}$ progressively decreased until it intercepted, at just about $100 \%$ of the strain, the viscous modulus $G^{\prime \prime}$ in the critical strain point $\left(\gamma G^{\prime}=G^{\prime \prime}\right)$, with consequent inversion of the moduli, thus indicating the breakage of the microgel structure. 
A

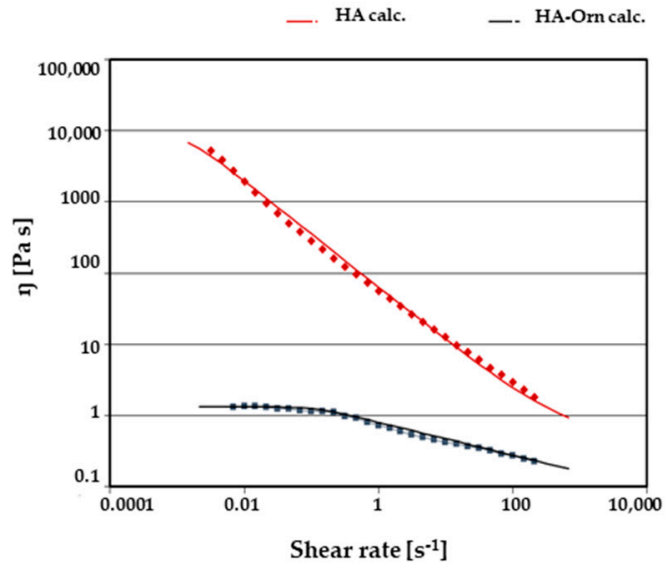

C

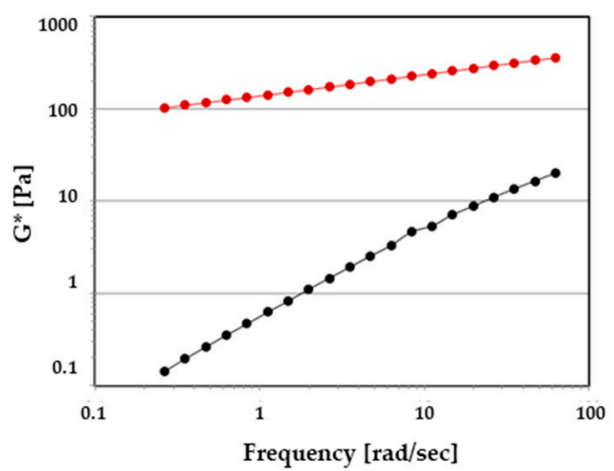

$\mathrm{B} \rightarrow \mathrm{HAG}^{\prime} \rightarrow \mathrm{HAG}^{\prime \prime}$

$\rightarrow$ HA.Orn G' $\multimap$ HA.Orn $G^{\prime \prime}$

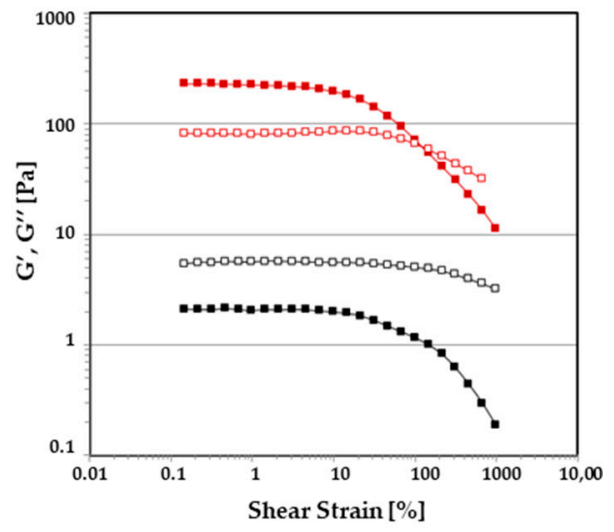

$\mathrm{D}$
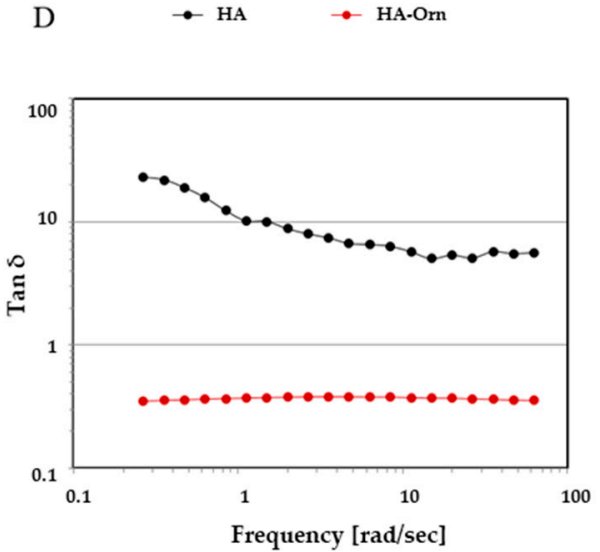

Figure 7. The trend of viscosity values (panel A), $G^{\prime}$ and $G^{\prime \prime}$ moduli (panel B), complex moduli $\left(G^{*}\right)$ (panel C), and damping factor $(\tan \delta)($ panel D).

Figure 7 (panel C) shows $\mathrm{G}^{*}$ trends as a function of the oscillation frequency applied to the sample. As expected, HA-Orn showed higher values of $\mathrm{G}^{*}$ (measured between 100 and $100 \mathrm{~Pa}$ ) than $\mathrm{HA}$, almost independent from the applied frequency. Instead, the $\mathrm{G}^{*}$ values for HA were strongly correlated with the changes in frequency, with the curve decreasing with decreasing values of frequency. The $\tan \delta$ values $>1$ indicated a liquid-like behaviour of HA dispersion and a greater dissipative capacity, while the HA-Orn sample (Figure 7, panel D) had values $<1$, indicating a prevalence of the elastic modulus. This rheological profile describes a typical weak-gel pattern, where the storage $G^{\prime}$ modulus dominated over the loss G" modulus throughout all the range of frequencies investigated. Overall, the elastic components always dominated over the viscous component, probably due to the presence of a high crosslinking degree in the hydrogel system.

\subsubsection{Dynamic Vapour Sorption}

To characterize the stability of the new polymeric network, a study was conducted on HA and HA-Orn under different humidity conditions (0-90\% relative humidity, $\mathrm{RH})$ using dynamic vapor absorption (DVS). The resulting moisture absorption-desorption isotherms (Figure S1) confirmed the typical trend of a hygroscopic HA-based polymer. In agreement with the literature [54,55], HA showed the water content increased linearly up to $29.3 \%$ in response to an $\mathrm{RH}$ increase from 0 to $70 \%$. From $70-90 \% \mathrm{RH}$, the moisture absorption increased rapidly, leading to a water content of $63.1 \%$. This rapid increase in moisture absorption is likely due to the hydrogel's remarkable ability to retain moisture under high $\mathrm{RH}$ conditions. HA-Orn cross-linking showed a final water content value of $37.1 \%$ at 
$90 \% \mathrm{RH}$. This behavior is in accordance with the characteristics of the novel cross-linking process that leads to a reduction in the polymer's ability to absorb water [56,57].

Desorption curves of HA and HA-Orn (Figure S1) showed a similar profile to the absorption curves. Minimal hysteresis phenomena were observed, indicating that despite being sensitive to moisture, this effect was reversible. These results indicate that, despite the modification due to the crosslinking process, the HA-Orn polymer preserved part of the water-retention capacity of its precursor HA and therefore its properties. At the same time, the cross-linking process made it less susceptible to water absorption, which excludes permanent alterations in the polymer structure.

\subsection{In Vitro Degradation}

To provide a cross-linking efficiency profile and information about the biodegradability of the new hydrogel, it is essential to define the field of application. In general, in vitro degradation offers preliminary proof of the resistance that the new biomaterial has acquired with the crosslinking process. As the concentration of hyaluronidases is tissue-specific, it is difficult to predict the real concentration in vivo. In this study, the concentration of hyaluronidases used was 50 units $/ \mathrm{mL}$, in line with most of the concentrations used in the literature $[58,59]$ for the same assay $(10-100$ units $/ \mathrm{mL})$; the molecular weight of the samples under examination was also considered. The chosen concentration proved to be an excellent compromise to be able to observe the degradation profile of both HA and its cross-linked derivative over a sufficiently long period of $24 \mathrm{~h}$. The in vitro degradation assay was performed by Bovine testes hyaluronidase as a hydrolytic enzyme to mimic the in vivo conditions where the enzyme cleaves the $\beta 1-4$ linkages, yielding fragments with $\mathrm{N}$-acetylglucosamine (NAG) at the reducing terminus and glucuronic acid at the nonreducing end. The amount of glucuronic acid (GlcA) released from samples was tested using the Carbazole colorimetric assay according to the method originally described by Bitter et al. [60] based on the quantitative colorimetric reaction through two consecutive steps: hydrolysis of the HA supernatant in sulfuric acid to generate GlcA and NAG monomers and development of the colorimetric reaction between GlcA and Carbazole.

The amount of glucuronic acid (GlcA) released from the native HA sample was shown to be greater than the cross-linked amount (Figure S2). Its maximum value was reached at $240 \mathrm{~min}(159.532 \mu \mathrm{g} / \mathrm{mL})$ and then remained almost unchanged, which means that the GlcA produced by the degradation of $15 \mathrm{mg}$ of $\mathrm{HA}$ reached its maximum value. Complete degradation did not occur up to $24 \mathrm{~h}$ incubation for the cross-linked hydrogel. Cross-linked HA-Orn instead showed insoluble fractions after $24 \mathrm{~h}$, with a released GlcA value of $113.5 \mu \mathrm{g} / \mathrm{mL}$. HA-Orn after $2 \mathrm{~h}$ of degradation released $15.9 \% \mathrm{GlcA}$, while the native HA released $57.2 \%(91.42 \mu \mathrm{g} / \mathrm{mL})$ of the total content. The absence of a plateau effect suggests that the degradation process was not completed within the $24 \mathrm{~h}$. This significantly reduced biodegradation rate, compared to unmodified HA, can be considered an advantage for HA-Orn's future clinical applications and for the development of delivery systems.

\subsection{MTS Cytotoxicity Assay}

The use of HA, as treatment of inflammatory airway pathologies, is well known [7-10] as previously described. For this reason, an in vitro study was conducted on lung adenocarcinomaderived epithelial Calu-3 and H441, representative of both the upper and lower lung regions to evaluate the safety of the new product for possible respiratory applications. The cytotoxicity of HA and HA-Orn polymers was evaluated at different concentrations by MTS assay. As shown in Figure 8, no cytotoxic effects were observed on Calu-3 cells exposed up to $0.3 \%$ of both formulations, whereas a significant decrease was observed in H441 cells treated with HA from $0.009 \%$. However, exposure of H441 to the HA-Orn polymer showed no cytotoxic effects up to $0.075 \%$. Overall, these results indicate that Calu-3 cells are more tolerant to the HA and HA-Orn polymers than $\mathrm{H} 441$ and that $\mathrm{H} 441$ cells are more sensitive to HA than to the HA-Orn polymer. Thus, HA-Orn could be considered for targeting the lower regions of the lung. 

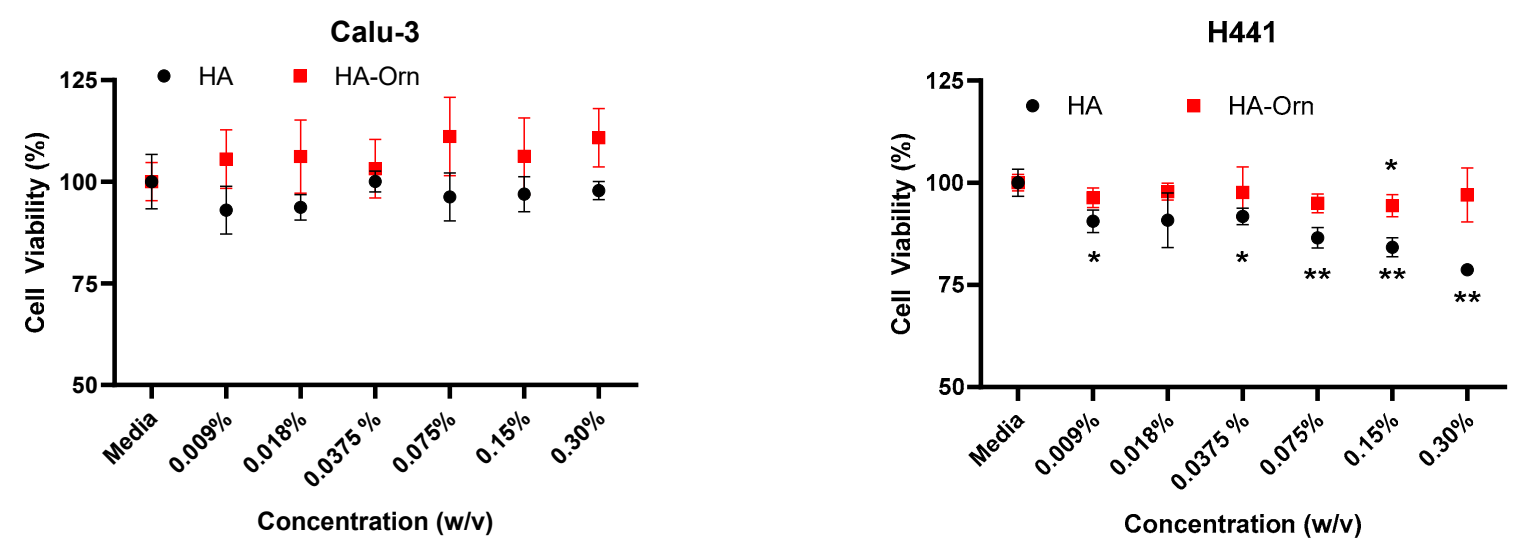

Figure 8. Cell viability was expressed as a percentage of control for Calu- 3 and H441 cell lines after 24 h of exposure to HA and HA-Orn using MTS assay ( $n=3$; mean \pm St Dev). Statistical differences between the control and treatments were determined using an unpaired t-test with Welch's correction (GraphPad Prism), and significance was considered when $p<0.05\left({ }^{*} p<0.05 ;{ }^{* *} p<0.01\right)$.

\section{Conclusions}

In summary, we designed and synthesized a new hyaluronic acid derivative crosslinked by an ornithine derivative. This material was further characterized for its physicochemical characteristics, cytotoxicity, and improved resistance to enzymatic degradation. Using CDMT as an activating agent and the amino acid Ornithine methyl ester as a crosslinking agent, we obtained a new product confirmed by the formation of the new $\mathrm{C}=\mathrm{O}$ amide bond, with a satisfactory degree of modification. HA-Orn showed a rheological profile attributable to an hydrogel, with a swelling ratio that can be modulated by $\mathrm{pH}$. HA-Orn is an interesting new material that could be utilized either as an active molecule or as an innovative polymeric system for drug delivery. The significant safety profile observed in lung cells was the starting point for the ongoing anti-inflammatory tests of HA-Orn on lung cells to evaluate its potential use as an adjuvant treatment for lung delivery. This behavior is currently under investigation, and ongoing studies will hopefully confirm the above stated potential.

\section{Patents}

This work was filed as patent application N $N^{\circ} 102019000024117$ on 16 December 2019 by the University of Ferrara.

Supplementary Materials: The following are available online at https:/ /www.mdpi.com/article/10 .3390/pharmaceutics13101672/s1, Figure S1: DVS isotherms of two cycles of moisture sorption and desorption of HA (black lines) and HA-Orn (red lines), Figure S2: Glucuronic acid released from in vitro degradation of $\mathrm{HA}$ and $\mathrm{HA}-\mathrm{Orn}$ in $\mathrm{PBS}, \mathrm{pH} 7.4$ at $37^{\circ} \mathrm{C}$ in the presence of $50 \mathrm{U} / \mathrm{mL}$ of hyaluronidase.

Author Contributions: Conceptualization, S.V., A.B. and S.M.; Data curation, E.D., S.V. and A.B.; Formal analysis, A.B.; Funding acquisition, S.V., A.B. and S.M.; Investigation, S.S., G.T., A.S., D.M.S., L.G.D.R. and A.B.; Methodology, S.S., D.M.S., L.G.D.R. and S.V.; Project administration, S.V. and S.M.; Resources, L.C., M.T., S.V. and A.B.; Supervision, L.C., M.T. and S.V.; Validation, S.V.; Writingoriginal draft, S.S. and A.B.; Writing—review \& editing, D.T., D.M.S., L.G.D.R., S.V., A.B. and S.M All authors have read and agreed to the published version of the manuscript.

Funding: This research was funded by Istituto Ganassini S.p.a. (Grant 2018, 2019, 2020 to S.S. PhD programme), University of Ferrara (Grant FIR 2020 to A.B.) and Ambrosialab (Grant 2020 to S.V.).

Data Availability Statement: The data presented in this study are available within the article and Supplementary Materials.

Acknowledgments: The authors gratefully thank Alberto Casolari for technical assistance. 
Conflicts of Interest: The authors declare no conflict of interest. The company had no role in the design of the study; in the collection, analyses, or interpretation of data; in the writing of the manuscript, and in the decision to publish the results.

\section{References}

1. Schanté, C.; Zuber, G.; Herlin, C.; Vandamme, F. Chemical modifications of hyaluronic acid for the synthesis of deriva-tives for a broad range of biomedical applications. Carbohydr. Polym. 2011, 85, 469-489. [CrossRef]

2. Laffleur, F.; Dachs, S. Development of novel mucoadhesive hyaluronic acid derivate as lubricant for the treatment of dry eye syndrome. Ther. Deliv. 2015, 6, 1211-1219. [CrossRef]

3. Weigel, P.; Fuller, G.; LeBoeuf, R.D. A model for the role of hyaluronic acid and fibrin in the early events during the in-flammatory response and wound healing. J. Theor. Biol. 1986, 119, 219-234. [CrossRef]

4. Aya, K.L.; Stern, R. Hyaluronan in wound healing: Rediscovering a major player. Wound Repair Regen. 2014, $22,579-593$. [CrossRef]

5. Borzacchiello, A.; Netti, P.A.; Ambrosio, L.; Nicolais, L. Hyaluronic acid derivatives mimic the rheological properties of vitreous body. In New Frontiers in Medical Sciences: Redefining Hyaluronan; Elsevier: Amsterdam, The Netherlands, 2000; pp. $192-202$.

6. Thambi, T.; Giang Phan, V.H.; Kim, S.H.; Le, T.; Lee, D. Hyaluronic acid decorated pH- and Temperature-induce injecta-ble bioconjugates for sustained delivery of bioactive factors and highly efficient wound regeneration. New J. Chem. 2019, $43,18979$. [CrossRef]

7. Furnari, M.; Termini, L.; Traverso, G.; Barrale, S.; Bonaccorso, M.; Damiani, G.; Lo Piapro, C.; Collura, M. Nebulized hy-pertonic saline containing hyaluronic acid improves tolerability in patients with cystic fibrosis and lung disease compared with nebulized hypertonic saline alone: A prospective, randomized, double-blind, controlled study. Ther. Adv. Respir. Dis. 2012, 6, 315-322. [CrossRef]

8. Garantziotis, S.; Brezina, M.; Castelnuovo, P.; Drago, L. The role of hyaluronan in the pathobiology and treatment of res-piratory disease. Am. J. Physiol. Lung Cell Mol. Physiol. 2016, 310, L785-L795. [CrossRef]

9. Gavina, M.; Luciani, A.; Villella, V.R.; Esposito, S.; Ferrari, E.; Bressani, I.; Casale, A.; Bruscia, E.M.; Maiuri, L.; Raia, V. Nebulized Hyaluronan Ameliorates lung inflammation in cystic fibrosis mice. Pediatr. Pulmonol. 2012, 48, 761-771. [CrossRef]

10. Petrigni, G.; Allegra, L. Aerosolised hyaluronic acid prevents exercise-induced bronchoconstriction, suggesting novel hy-potheses on the correction of matrix defects in asthma. Pulm. Pharmacol. Ther. 2006, 19, 166-171. [CrossRef]

11. Rahman, I.; Adcock, I.M. Oxidative stress and redox regulation of lung inflammation in COPD. Eur. Respir. J. 2006, 28, 219-242. [CrossRef]

12. Carro, L.M.; Martínez-García, M.A. Use of Hyaluronic Acid (HA) in Chronic Airway Diseases. Cells 2020, 9, 2210. [CrossRef]

13. Robert, L.; Robert, A.-M.; Renard, G. Biological effects of hyaluronan in connective tissues, eye, skin, venous wall. Role in aging. Pathol. Biol. 2010, 58, 187-198. [CrossRef]

14. Baumann, L. Dermal fillers. J. Cosmet. Dermatol. 2004, 3, 249-250. [CrossRef]

15. Gatej, I.; Popa, M.; Rinaudo, M. Role of the $\mathrm{pH}$ on Hyaluronan Behavior in Aqueous Solution. Biomacromolecules 2005, 6, 61-67. [CrossRef]

16. Muhn, C.; Rosen, N.; Solish, N.; Bertucci, V.; Lupin, M.; Dansereau, A.; Weksberg, F.; Remington, B.K.; Swift, A. The evolving role of hyaluronic acid fillers for facial volume restoration and contouring: A Canadian overview. Clin. Cosmet. Investig. Dermatol. 2012, 5, 147-158. [CrossRef]

17. Hašová, M.; Crhák, T.; Šafránková, B.; Dvořáková, J.; Muthný, T.; Velebný, V.; Kubala, L. Hyaluronan minimizes effects of UV irradiation on human keratinocytes. Arch. Dermatol. Res. 2011, 303, 277-284. [CrossRef]

18. Trommer, H.; Wartewig, S.; Böttcher, R.; Pöppl, A.; Hoentsch, J.; Ozegowski, J.H.; Neubert, R.H. The effects of hyaluronan and its fragments on lipid models exposed to UV irradiation. Int. J. Pharm. 2003, 254, 223-234. [CrossRef]

19. Girish, K.; Kemparaju, K. The magic glue hyaluronan and its eraser hyaluronidase: A biological overview. Life Sci. 2007, 80, 1921-1943. [CrossRef]

20. Jedrzejas, M.J.; Stern, R. Structures of vertebrate hyaluronidases and their unique enzymatic mechanism of hydrolysis. Proteins Struct. Funct. Bioinform. 2005, 61, 227-238. [CrossRef]

21. Knopf-Marques, H.; Pravda, M.; Wolfova, L.; Velebny, V.; Schaaf, P.; Vrana, N.; Lavalle, P. Hyaluronic Acid and Its De-rivatives in Coating and Delivery Systems: Applications in Tissue Engineering, Regenerative Medicine and Immunomod-ulation. Adv. Healthc. Mater. 2016, 5, 2841-2855. [CrossRef]

22. Luo, Y.; Prestwich, G.D. Synthesis and Selective Cytotoxicity of a Hyaluronic Acid-Antitumor Bioconjugate. Bioconjugate Chem. 1999, 10, 755-763. [CrossRef]

23. Drobnik, J. Hyaluronan in drug delivery. Adv. Drug Deliv. Rev. 1991, 7, 295-308. [CrossRef]

24. Choi, K.Y.; Min, K.H.; Na, J.H.; Choi, K.; Ki, K.; Park, J.H.; Kwon, I.C.; Jeong, S.Y. Self-assembled hyaluronic acid nano-particles as a potential drug carrier for cancer therapy: Synthesis, characterization, and in vivo biodistribution. J. Mater. Chem. 2009, 19, 4102-4107. [CrossRef]

25. Shimojo, A.A.M.; Pires, A.M.B.; Lichy, R.; Rodrigues, A.A.; Santana, M.H.A. The crosslinking degree controls the mechanical, rheological, and swelling properties of hyaluronic acid microparticles. J. Biomed. Mater. Res. Part A 2014, 103, 730-737. [CrossRef] 
26. La Gatta, A.; Schiraldi, C.; Papa, A.; D’Agostino, A.; Cammarota, M.; Rosa, A.; Rosa, M. Hyaluronan scaffolds via di-glycidyl ether cross-linking: Toward improvements in composition and performance. Carbohydr. Polym. 2013, 96, 536-544. [CrossRef]

27. Sung, H.; Huang, R.; Huang, L.; Tsai, C.; Chiu, C. Feasibility study of a natural crosslinking reagent for biologi-cal tissue fixation. J. Biomed. Mater. Res. 1998, 42, 560-567. [CrossRef]

28. Ferretti, M.; Marra, K.K.; Defail, A.; Chu, C. Controlled in vivo degradation of genipin crosslinked polyethylene glycol hy-drogels within osteochondral defects. Tissue Eng. 2006, 12, 2657-2663. [CrossRef]

29. Tan, H.; Chu, C.R.; Payne, K.; Marra, K.G. Injectable in situ forming biodegradable chitosan-hyaluronic acid based hydrogels for cartilage tissue engineering. Biomaterials 2009, 30, 2499-2506. [CrossRef]

30. Ye, D.; Chang, C.; Zhang, L. High-strenght and tought cellulose hydrogels chemically dual cross-linked by using low- and high-molecular-weight cross-linkers. Biomacromolecules 2019, 20, 1989-1995. [CrossRef]

31. Abatangelo, G.; Vindigni, V.; Avruscio, G.; Pandis, L.; Brun, P. Hyaluronic Acid: Redefining Its Role. Cells 2020, 9, 1743. [CrossRef]

32. Zamboni, F.; Ryan, E.; Culebras, M.; Collins, M.N. Labile crosslinked hyaluronic acid via urethane formation using bis $(\beta-$ isocyanatoethyl) disulphide with tuneable physicochemical and immunomodulatory properties. Carbohydr. Polym. 2020, 245, 116501. [CrossRef]

33. Zamboni, F.; Okoroafor, C.; Ryan, M.P.; Pembroke, J.T.; Strozyk, M.; Culebras, M.; Collins, M.N. On the bacteriostatic ac-tivity of hyaluronic acid composite films. Carbohydr. Polym. 2021, 260, 117803. [CrossRef]

34. How, K.N.; Yap, W.H.; Lim, C.L.H.; Goh, B.H.; Lai, Z.W. Hyaluronic acid-mediated drug delivery system targeting for inflammatory skin diseases: A mini review. Front. Pharmacol. 2020, 11, 1105. [CrossRef]

35. Chang, K.C.; Chen, W.C.; Haung, S.M.; Liu, S.M.; Lin, C.L. Effects of Hinokitiol and dicalcium phosphate on the oste-oconduction and antibacterial activity of gelatin-hyaluronic acid crosslinked hydrogel membrane in vitro. Pharmaceuticals 2021, $14,802$. [CrossRef]

36. Arezki, N.R.; Williams, A.C.; Cobb, A.J.A.; Brown, M. Design, synthesis and characterization of linear unnatural amino acids for skin moisturization. Int. J. Cosmet. Sci. 2016, 39, 72-82. [CrossRef]

37. Thambi, T.; Giang Phan, V.H.; Kim, S.H.; Le, T.; Doung, H.T.D.; Lee, D. Smart injectable biogels based on hyaluronic acid bioconiugates finely substituted with poly( $\beta$-amino ester urethane) for cancer therapy. Biomater. Sci. 2019, 7, 5424. [CrossRef]

38. Silva, A.C.; Rodrigues, S.C.; Caldeira, J.; Nunes, A.M.; Sampaio-Pinto, V.; Resende, T.P.; Oliveira, M.J.; Barbosa, M.A.; Thorsteinsdóttir, S.; Nascimento, D.S.; et al. Three-dimensional scaffolds of fetal decellularized hearts exhibit en-hanced potential to support cardiac cells in comparison to the adult. Biomaterials 2016, 104, 52-64. [CrossRef]

39. Yasuda, K.; Armstrong, R.; Cohen, R. Shear flow properties of concentrated solutions of linear and star branched polysty-renes. Rheol. Acta. 1981, 20, 163-178. [CrossRef]

40. Lapasin, R.; Pricl, S. Rheology of Industrial Polysaccharides: Theory and Applications; Blackie Academic \& Professional: London, UK, 1995.

41. Tadros, T. Application of rheology for assessment and prediction of the long-term physical stability of emulsions. Adv. Colloid Interface Sci. 2004, 108, 227-258. [CrossRef]

42. Bergman, K.; Elvingson, C.; Hilborn, J.; Svensk, G.; Bowden, T. Hyaluronic Acid Derivatives Prepared in Aqueous Media by Triazine-Activated Amidation. Biomacromolecules 2007, 8, 2190-2195. [CrossRef]

43. Ford, J.; Timmins, P. Pharmaceutical Thermal Analysis: Techniques and Applications; Ellis Horwood: Chichester, UK, 1989.

44. Collins, M.; Birkinshaw, C. Comparison of the effectiveness of four different crosslinking agents with hyaluronic acid hy-drogel films for tissue-culture applications. J. Appl. Polym. Sci. 2007, 104, 3183-3191. [CrossRef]

45. Collins, N.; Birkinshaw, C. Physical properties of crosslinked hyaluronic acid hydrogels. J. Mater. Sci. Mater. Med. 2008, 19, 3335-3343. [CrossRef]

46. Kafedjiiski, K.; Jetti, R.K.; Föger, F.; Hoyer, H.; Werle, M.; Hoffer, M.; Bernkop-Schnürch, A. Synthesis and in vitro evaluation of thiolated hyaluronic acid for mucoadhesive drug delivery. Int. J. Pharm. 2007, 343, 48-58. [CrossRef]

47. Bashir, S.; Hina, M.; Iqbal, J.; Rajpar, A.H.; Mujtaba, M.A.; Alghamdi, N.A.; Wageh, S.; Ramesh, K.; Ramesh, S. Funda-mental Concepts of Hydrogels: Synthesis, Properties, and Their Applications. Polymers 2020, 12, 2702. [CrossRef]

48. Smart, J.D. The basics and underlying mechanisms of mucoadhesion. Adv. Drug Deliv. Rev. 2005, 57, 1556-1568. [CrossRef]

49. Luo, Y.; Kirker, K.R.; Prestwich, G.D. Cross-linked hyaluronic acid hydrogel films: New biomaterials for drug delivery. J. Control. Release 2000, 69, 169-184. [CrossRef]

50. Manconi, M.; Manca, M.; Valenti, D.; Escribano, D.; Hillaireau, E.; Fadda, A.; Fattal, E. Chitosan and hyaluronan coated liposomes for pulmonary administration of curcum. Int. J. Pharm. 2017, 525, 203-210. [CrossRef]

51. Egbu, R.; Brocchini, S.; Khaw, P.; Awwad, S. Antibody loaded collapsible hyaluronic acid hydrogels for intraocular deliv-ery. Eur. J. Pharm. Biopharm. 2018, 124, 95-103. [CrossRef]

52. Schneider, L.; Korber, A.; Grabbe, S.; Dissemond, J. Influence of pH on wound-healing: A new perspective for wound-therapy? Arch. Dermatol. Res. 2007, 298, 413-420. [CrossRef]

53. Shukla, V.; Shukla, D.; Tiwary, S.; Agrawal, S.; Rastogi, A. Evaluation of pH measurement as a method of wound assess-ment. J. Wound Care 2007, 16, 291-294. [CrossRef]

54. Panagopoulou, A.; Molina, J.V.; Kyritsis, A.; Pradas, M.M.; Lluch, A.V.; Ferrer, G.G.; Pissis, P. Glass Transition and Water Dynamics in Hyaluronic Acid Hydrogels. Food Biophys. 2013, 8, 192-202. [CrossRef] 
55. Ghosh, K.; Shu, X.M.; Mou, R.; Lombardi, J.; Prestwich, G.D.; Rafailovich, M.H.; Clark, R.A.F. Rheological characteriza-tion of in situ cross-linkable hysluronan hydrogels. Biomacromolecules 2005, 6, 2857-2865. [CrossRef] [PubMed]

56. Guilherme, M.R.; Campese, G.M.; Radovanovic, E.; Rubira, A.; Feitosa, J.P.; Muniz, E.C. Morphology and water affinity of superabsorbent hydrogels composed of methacrylated cashew gum and acrylamide with good mechanical properties. Polymer 2005, 46, 7867-7873. [CrossRef]

57. Noh, I.; Kim, G.C.; Kim, M.; Choi, Y.; Kim, M.; Park, Y.; Lee, K.; Kim, I.; Hwang, S.; Tae, G. Effects of cross-linking molec-ular weights in a hyaluronic acid-poly(ethylene oxide) hydrogel network on its properties. Biomed. Mater. 2006, 1, 116-123. [CrossRef] [PubMed]

58. La Gatta, A.; Schiraldi, C.; Papa, A.; De Rosa, M. Comparative analysis of commercial dermal fillers based on crosslinked hyaluronan: Physical characterization and in vitro enzymatic degradation. Polym. Degrad. Stab. 2011, 96, 630-636. [CrossRef]

59. La Gatta, A.; Papa, A.; Schiraldi, C.; De Rosa, M. Hyaluronan dermal fillers via crosslinking with 1,4-butandiol diglyc-idyl ether: Exploitation of heterogeneous reaction conditions. J. Biomed. Mater Res. B Appl. Biomater. 2016, 104, 9-18. [CrossRef] [PubMed]

60. Bitter, T.; Muir, H. A modified uronic acid carbazole reaction. Anal. Biochem. 1962, 4, 330-334. [CrossRef] 